\title{
NOTES
}

\section{Synthesis and $Q, e$ Values of New Fluorine-Containing Monomer: Pentafluorophenylmethyl Methacrylate}

\author{
Tadashi NARITA, * Tokio HagIwARA, Hiroshi HamanA, \\ Keitaro DEI, and Yukinori SHOJI \\ Department of Environmental Engineering, Saitama Institute of Technology, \\ 1690 Fusaiji, Okabe, Saitama 369-02, Japan
}

(Received April 8, 1989)

\begin{abstract}
KEY WORDS Pentafluorophenylmethyl Methacrylate / Radical Copolymerization / Monomer Reactivity Ratios / $Q, e$-Values /
\end{abstract}

Fluorine-containing polymers have recently come to attract much attention in the fields of $\mathrm{X}$-ray and electron beam lithography. In a preceding paper, it was pointed out that the reactivity of fluorine-containing acrylates and methacrylates is strongly influenced by the high electron-withdrawing inductive effects of fluoroalkyl groups. ${ }^{1}$ The high $e$-values of fluoroalkyl acrylates and methacrylates, and methyl 2-trifluoromethylacrylate ${ }^{2}$ have been reported.

A more detailed study has revealed that the anionic polymerization activity of fluoroalkyl methacrylates is affected by fluoroalkyl moieties. 2,2,2-Trifluoroethyl methacrylate yields the polymer by the initiations of 1,1-diphenylhexyllithium and $\mathrm{LiZnC}_{4} \mathrm{H}_{9}\left(\mathrm{C}_{2} \mathrm{H}_{5}\right)_{2},{ }^{3}$ and 2,2,2-trifluoro-1-trifluoromethylethyl methacrylate by triethylaluminum. ${ }^{4}$ Ethyl 2-trifluoromethylacrylate has been reported the most active monomer of ethyl, 2,2,2-trifluoroethyl, and 2,2,2-trifluoro-1-trifluoromethylethyl 2-trifluoromethylacrylates in the case of the anionic polymerization initiated with $t-\mathrm{C}_{4} \mathrm{H}_{9} \mathrm{OLi}$, and the reactivities of these monomers decreases with increase in trifluoromethyl-substitution at ester alkyl group..$^{5,6}$

In order to obtain information on the effect of fluorinated phenyl group on the polymerization reactivity of vinyl monomers, the present paper is concerned with the synthesis and Alfrey-Price's $Q, e$ values of pentafluorophenylmethyl methacrylate (PFPMA) as a new fluorine-containing monomer.

\section{EXPERIMENTAL}

\section{Reagents}

Pentafluorophenylmethanol (from Japan Catalytic Chemical Ind.) was distilled under reduced pressure, bp $87^{\circ} \mathrm{C} / 25 \mathrm{mmHg}$, mp 37$38.5^{\circ} \mathrm{C}$. Methacryloyl chloride (from Japan Catalytic Chemical Ind.) was purified by distillation. Commercial triethylamine, styrene, diethyl ether, and benzene were purified by the usual methods and distilled under purified nitrogen atmosphere. $\alpha, \alpha^{\prime}$-Azobisisobutyronitrile (AIBN) was recrystallized from methanol.

\section{Synthesis of Pentafluorophenylmethyl Methac- rylate (PFPMA) \\ To a magnetically stirred diethyl ether $(200 \mathrm{ml})$ solution of pentafluorophenylmeth- anol $(198 \mathrm{~g}, 1 \mathrm{~mol})$ and triethylamine $(145 \mathrm{~g}$, $1.43 \mathrm{~mol}$ ) in a 11 round-bottom flask with a}

\footnotetext{
* To whom correspondence should be addressed.
} 
reflux condenser and calcium chloride drying tube, methacryloyl chloride $(105 \mathrm{~g}, 1 \mathrm{~mol})$ was added dropwise under reflux of the solvent by reaction heat. It took over $3 \mathrm{~h}$. The reaction mixture was further refluxed for $1.5 \mathrm{~h}$, and then cooled to room temperature. After water $(200 \mathrm{ml})$ was added, the aqueous mixture was extracted twice with diethyl ether. The ether layer was washed with aqueous sulfuric acid $(10 \%)$ three times and then dried overnight over sodium sulfate in the presence of $t$ butyl catechol as radical polymerization inhibitor. The ether was removed by evaporation and PFPMA was collected by distillation under reduced pressure, bp $85.4^{\circ} \mathrm{C} / 4 \mathrm{mmHg}$, yield
$58 \%, d^{25} 1.64 \mathrm{~g} \mathrm{~cm}^{-3}$. PFPMA was further purified by refluxing over calcium hydride and distillation.

\section{Copolymerization}

Radical copolymerizations of PFPMA ( $\left.\mathbf{M}_{1}\right)$ with styrene $\left(\mathrm{M}_{2}\right)$ were carried out in benzene solutions with AIBN as the initiator at $70^{\circ} \mathrm{C}$ for $20 \mathrm{~min}$ in order to keep the yields of the copolymers under $10 \mathrm{wt} \%$. The copolymers formed were precipitated in methanol, isolated by filtration, and dried in vacuo. The compositions of the copolymers were determined by ${ }^{1} \mathrm{H}$ NMR areal ratios of the peaks assigned to methyl and phenyl protons, respectively.

(A)

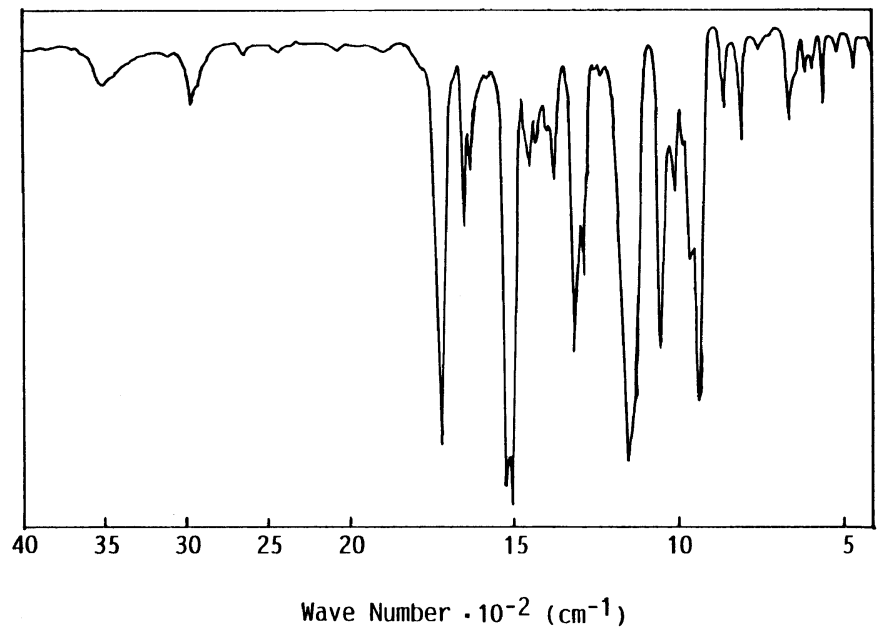

(B)

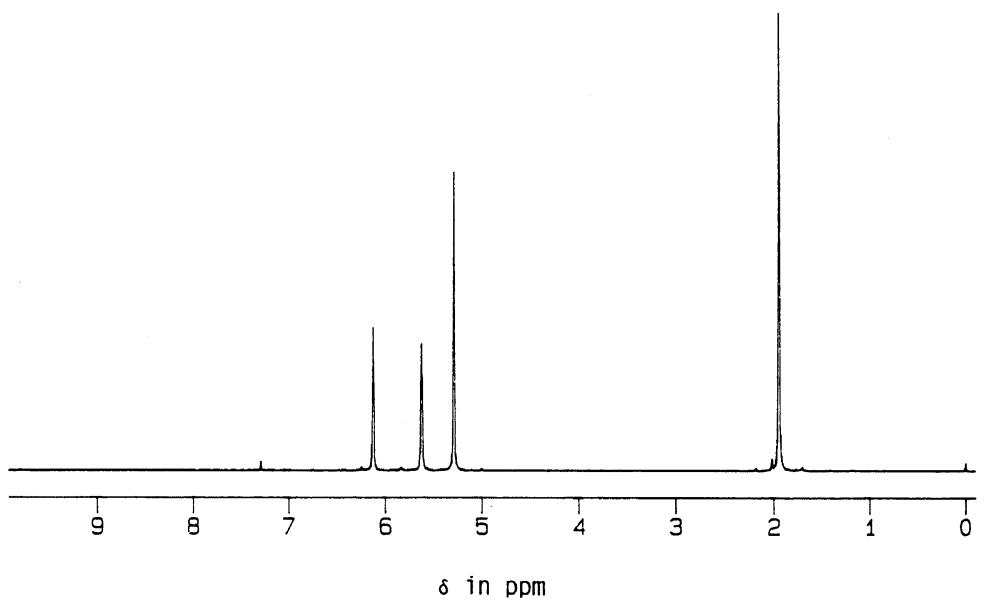

Figure 1. IR (A) and ${ }^{1} \mathrm{H}$ NMR (B) of pentafluorophenylmethyl methacrylate. 
Monomer reactivity ratios $\left(r_{1}\right.$ and $\left.r_{2}\right)$ were determined by the nonliner least-square fitting method, using a computer.

\section{Measurements}

${ }^{1} \mathrm{H}$ NMR spectra were recorded in deuteriochloroform $\left(\mathrm{CDCl}_{3}\right)$ on JEOL JNMGSX 270. Gel permeation chromatogram was measured with a TOYO SODA HLC-802A equipped with a TSK gel G4000HXL-G3000HXL-G2000HXL column series using tetrahydrofuran (THF) as the eluent. Infrared (IR) spectra were obtained with a JASCO IR-700.

\section{RESULTS AND DISCUSSION}

Synthesis of Pentafluorophenylmethyl Methacrylate (PFPMA)

PFPMA was easily synthesized by the reaction of commercially available pentafluorophenylmethanol with methacryloyl chloride in the presence of triethylamine as a base. The yield of PFPMA was as much as $58 \%$. Only a small amount of PFPMA $(<1 \%)$ was produced by the addition of pyridine instead of triethylamine.

IR and ${ }^{1} \mathrm{H}$ NMR spectra of PFPMA are shown in Figure 1. Absorption observed at 1134,1631 , and $1727 \mathrm{~cm}^{-1}$ was assigned to pentafluorobenzyl group, carbon-carbon double bond, and carbonyl group, respectively (Figure 1(A)). Signals assignable to methyl, methylene and vinyl protons in ${ }^{1} \mathrm{H}$ NMR (Figure 1(B)) were observed at $\delta=1.96,5.32$, and $5.64-6.12 \mathrm{ppm}$, respectively, at an intensity ratio of $3: 2: 2$.

Radical Copolymerization of PFPMA $\left(M_{1}\right)$ with Styrene $\left(M_{2}\right)$

Homopolymers of PFPMA $(6.16 \mathrm{mmol}$ in feed) were produced in yields of $18.1 \%(6 \mathrm{~h})$, $22.0 \%(12 \mathrm{~h})$, and $29.2 \%(24 \mathrm{~h})$ by radical polymerization initiated by AIBN $(0.4 \mathrm{mmol})$ in benzene $(9 \mathrm{ml})$ at $70^{\circ} \mathrm{C}$. Poly(PFPMA) melted at $120^{\circ} \mathrm{C}$ and gave a colorless solid when cooled to room temperature. The molecular

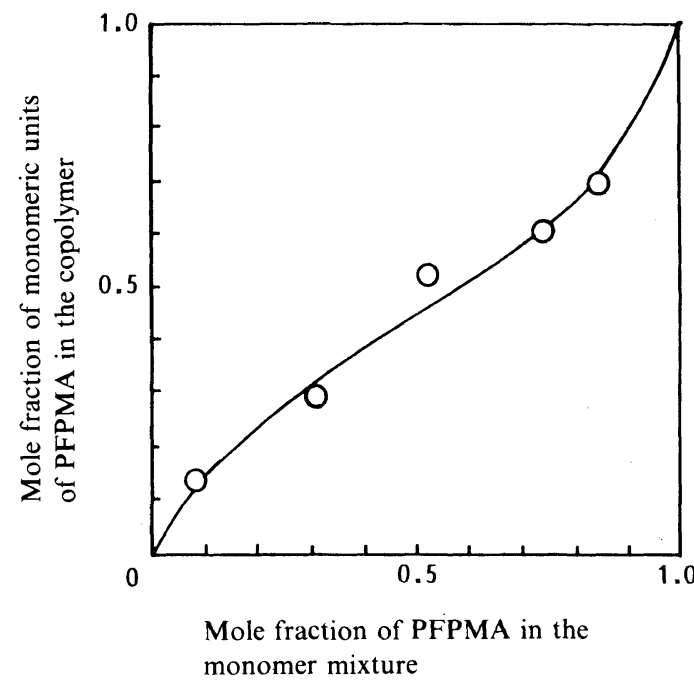

Figure 2. Copolymer composition curve of pentafluorophenylmethyl methacrylate $\left(M_{1}\right)$ with styrene $\left(\mathrm{M}_{2}\right)$.

weight of poly(PFPMA) obtained at $24 \mathrm{~h}$ was $9.8 \times 10^{3}$ as calculated from the GPC calibration curve based on standard polystyrene.

Copolymerizations of PFPMA with styrene were carried out in benzene solution at $70^{\circ} \mathrm{C}$ by AIBN to obtain monomer reactivity ratios. The monomer-copolymer composition curve is shown in Figure 2. The solid line in Figure 2 is the calculated monomer-copolymer composition curve from the monomer reactivity ratios, $r_{1}=0.33$ and $r_{2}=0.59$.

$Q, e$-values of Alfrey-Price's $Q, e$ scheme, calculated from the monomer reactivity ratios, are $Q=0.61$ and $e=0.48$, respectively. These values are similar to those for benzyl methacrylate $(Q, 0.70 ; e, 0.42)^{7}$ and methyl methacrylate $(Q, 0.73 ; e, 0.52)$. Thus possibly the fluorinated phenyl group has no influence on the polymerization reactivity of the vinyl group of PFPMA. However, the fluorinated phenyl group which has an electronwithdrawing inductive effect influenced the reactivity of the vinyl group of PFPMA in the case of anionic polymerization. PFPMA (6.2 mmol) gave no polymer with $n-\mathrm{C}_{4} \mathrm{H}_{9} \mathrm{Li}$ or $\mathrm{C}_{2} \mathrm{H}_{5} \mathrm{MgBr}(0.25 \mathrm{mmol})$ at $0^{\circ} \mathrm{C}$ in THF $(10 \mathrm{ml})$ 
after $24 \mathrm{~h}$, while MMA and benzyl methacrylate was polymerized under these conditions. ${ }^{8,9} \mathrm{~A}$ 'ate' complex $\left(\mathrm{LiZnC}_{4} \mathrm{H}_{9}\left(\mathrm{C}_{2} \mathrm{H}_{5}\right)_{2}{ }^{3}\right)$ and an organozinc compound $\left(\left[\mathrm{C}_{2} \mathrm{H}_{5} \mathrm{ZnO}\right.\right.$ $\left.\mathrm{CH}\left(\mathrm{CH}_{3}\right) \mathrm{CH}_{2} \mathrm{OCH}_{3}\right) \cdot\left(\mathrm{Zn}\left(\mathrm{OCH}\left(\mathrm{CH}_{3}\right) \mathrm{CH}_{2} \mathrm{O}-\right.\right.$ $\left.\left.\mathrm{CH}_{3}\right)_{2}\right],{ }^{10}$ inactive for the anionic polymerization of MMA though effective for vinyl ketones without side reaction, ${ }^{11}$ produced the polymer in moderate yields (30.2 and $84.0 \%$, respectively).

The investigation on difference in the polymerization reactivities of the monomers with fluorine-containing substituents in the polymerizations with the different propagating species, is now under way and the results will be presented elsewhere.

\section{REFERENCES}

1. T. Narita, T. Hagiwara, and H. Hamana, Makromol. Chem., Rapid Commun., 6, 5 (1985).

2. S. Iwatsuki, A. Kondo, and H. Harashima, Macromolecules, 17, 2473 (1984).

3. T. Narita, T. Hagiwara, and H. Hamana, Makromol. Chem., Rapid Commun., 6, 175 (1985).

4. T. Narita, T. Hagiwara, and H. Hamana, Nippon Kagaku Kaishi, 1945 (1985).

5. T. Narita, T. Hagiwara, H. Hamana, and T. Nara, Makromol. Chem., Rapid Commun., 6, 301 (1985).

6. T. Narita, T. Hagiwara, H. Hamana, and S. Maesaka, Polym. J., 20, 519 (1988).

7. L. J. Young, "Tabulation of $Q, e$-values" in "Polymer Handbook," 2nd ed, J. Brandrup and E. H. Immergut, Ed., Wiley, New York, N. Y., p II-400.

8. S. Bywater, Adv. Polym. Sci., 4, 66 (1965).

9. H. Yuki, K. Hatada, T. Niinomi, and Y. Kikuchi, Polym. J., 1, 36 (1970).

10. H. Kageyama, Y. Kai, N. Kasai, C. Suzuki, N. Yoshino, and T. Tsuruta, Makromol. Chem., Rapid Commun., 5, 89 (1984).

11. Y. Kawakami and T. Tsuruta, Bull. Chem. Soc. Jpn., 44, 247 (1971). 